\title{
Arachnoid cyst resulting in tonsillar herniation and syringomyelia in a patient with achondroplasia
}

\author{
Case report
}

\author{
Andrew M. Bauer, B.S., Diane M. Mueller, N.D., R.N., C.-F.N.P., AND \\ JOHN J. ORÓ, M.D.
}

Department of Surgery, Division of Neurological Surgery, University of Missouri-Columbia School of Medicine, Columbia, Missouri

\begin{abstract}
Achondroplasia has been associated with varying degrees of cervicomedullary and spinal compression, although usually in the pediatric population. Large arachnoid cysts have also been found to result in tonsillar herniation and syringomyelia. The authors present the case of a patient with achondroplasia who presented with symptoms of foramen magnum compression and syringomyelia, and who was subsequently found to have a large posterior fossa arachnoid cyst.

This 38-year-old woman with achondroplasia presented with an 8-month history of headache and numbness of the hands and fingers. Admission magnetic resonance (MR) imaging of the head and spine revealed a large arachnoid cyst in the posterior cranial fossa, a 6-mm tonsillar herniation consistent with an acquired Chiari malformation, and a large cervicothoracic syrinx. The patient was treated using suboccipital craniectomy, C-1 laminectomy, fenestration of the arachnoid cyst, and decompression of the acquired Chiari malformation with duraplasty.

Surgical decompression resulted in improvement of the presenting symptoms, adequate decompression of crowding at the foramen magnum, and resolution of the syrinx. Although there was only partial reduction in the retrocerebellar cisternal space on follow-up MR imaging, no residual symptoms were related to this.
\end{abstract}

KEY WORDS • Chiari malformation • syringomyelia • arachnoid cyst • achondroplasia

Achondroplasia, the most common form of bone dysplasia and the best-known form of congenital dwarfism, is caused by a disturbance of endochondral bone formation. . $16,16,19,20,24$ Neurological symptoms are identified in as many as $47 \%$ of patients with achondroplasia. Symptoms in children include psychomotor delay, hypotonia, feeding and sleep disorders, apnea, macrocrania with or without hydrocephalus, and compressive spinal syndromes. ${ }^{19}$ Cervicomedullary compression is also common in the pediatric population $^{20,24}$ and is almost always diagnosed and treated before adulthood. In the adult population of patients with achondroplasia, spinal stenosis with compression of the spinal cord results in many radicular pain syndromes., ${ }^{2,15,19}$ The neurological manifestations can be severe, with extreme cases resulting in death due to hydrocephalus or compression of the brainstem. Patients in all age groups with achondroplasia generally have a small cranial base, whereas the rest of the skull is normal in size. This size discrepancy may predispose patients to anomalous formation of the posterior fossa and foramen magnum, thus creating a smaller than normal posterior fossa.

Syringomyelia has been associated with many intracra-

Abbreviations used in this paper: $\mathrm{CSF}=$ cerebrospinal fluid; $\mathrm{MR}=$ magnetic resonance. nial and spinal anomalies. One theory is that syringomyelia results from obstruction of CSF flow at the level of the foramen magnum and the outlet of the fourth ventricle. ${ }^{1}$ Obstruction of CSF flow may lead to an increased pulsatile pressure within the spinal canal and may force CSF into the spinal cord..$^{18}$ This obstruction is most commonly caused by the Chiari malformation and crowding of the posterior fossa. The Chiari malformation has been traditionally defined as downward herniation of the cerebellar tonsils through the foramen magnum..$^{14}$ The average delay in diagnosis of a Chiari malformation is 5 years after the onset of symptoms, leaving ample time for the development of other complications such as syrinx..$^{5}$

Intracranial and posterior fossa mass lesions such as tumors or arachnoid cysts may also result in tonsillar herniation. Arachnoid cysts are benign collections of CSF within an anomalous arachnoid enclosure that account for approximately $1 \%$ of intracranial mass lesions. ${ }^{6}$ There have been several reports of large arachnoid cysts in the posterior fossa associated with syrinx. ${ }^{4,9,21,23}$ We describe the case of a patient with achondroplasia who presented with an 8month history of headache and neurological symptoms. Brain MR imaging revealed a large arachnoid cyst in the posterior fossa that was causing a 6-mm tonsillar herniation and a cervicothoracic syrinx. 


\section{CASE REPORT}

History. This 38-year-old woman with achondroplasia presented with an 8-month history of occipital shock-like headache that radiated to the temporal regions. The pain was not aggravated by Valsalva maneuvers. Concurrently, she noticed bilateral tone deafness, bilateral tingling of the fingers, numbness in her lower lip, and numbness in the back of her head, neck, and perineal region. She also reported a sharp pain radiating from the left scapular region anteriorly to the chest. Other complaints included dizziness, fatigue, depression, and impaired memory.

Examination. Physical examination revealed short stature with short arms and legs characteristic of achondroplasia. The initial neurological examination revealed diminished gag reflex bilaterally, and decreased sensation to light touch in the V1 and V2 distributions on the right side of the face and diffusely in the right arm and leg. Patellar reflexes were brisk. Results of the remainder of the neurological examination were normal.

A noncontrasted MR image of the brain revealed a large arachnoid cyst in the posterior fossa resulting in herniation of the tonsils $6 \mathrm{~mm}$ below the foramen magnum (Fig. 1). The posterior fossa measurements showed a long, thin supraocciput measuring $68 \mathrm{~mm}$ (normal $41.8 \pm 5.2 \mathrm{~mm}$ ), the clivus measured $37 \mathrm{~mm}$ (normal $40.4 \pm 5.1 \mathrm{~mm}$ ), and a reduced tentorial angle of $70^{\circ}$ (normal $82.5 \pm 7.2^{\circ}$ ) was observed. Sagittal MR imaging of the cervical spine revealed a large syrinx spanning the C6-T1 vertebral bodies (Fig. 2).

Operation. After review of the neuroimaging studies and discussion of treatment options with the patient, she elected to proceed with surgery. In the operating room, after in- duction of general anesthesia, the patient was placed prone with her head supported in a Mayfield headrest. Hair covering an 8-cm patch in the midline of the occiput centered on the inion was shaved, and an incision was created from just above the inion to C-2. After the posterior fossa and lamina of C-1 were exposed, a craniotomy was performed extending from just above the inion to the foramen magnum. The C-1 lamina was removed. Opening the posterior fossa and upper cervical dura mater revealed a large arachnoid cyst filled with CSF and encompassing the upper portion of the posterior fossa. The cyst did not extend to the foramen magnum, where the tonsils were impacted and herniated to the level of $\mathrm{C}-1$. The cerebellar hemispheres appeared to be compressed anteriorly.

The posterior wall of the cyst was opened and a portion of the anterior wall was fenestrated into the quadrigeminal cistern on the right (prominent veins on the left prohibited fenestration). Cyst wall excision and fenestration did not change the impacted position of the tonsils, so their inferomedial aspects were gently shrunk using bipolar cautery. A $3 \times 4-\mathrm{cm}$ triangular pericranial graft was harvested from under the scalp above the inion and incorporated into the dural closure at the foramen. The bone flap was then trimmed to provide a $2 \times 3-\mathrm{cm}$ craniectomy at the foramen magnum and was reattached with microplates. The wound was closed in layers and the patient was extubated and transferred to the postanesthesia care unit, where she had an uneventful recovery course. She continued to convalesce well and was discharged on the 3rd postoperative day.

Postoperative Course. At her 3-month follow-up review, the patient reported resolution of her occipital and temporal pain, dizziness, and lip numbness, and improvement in
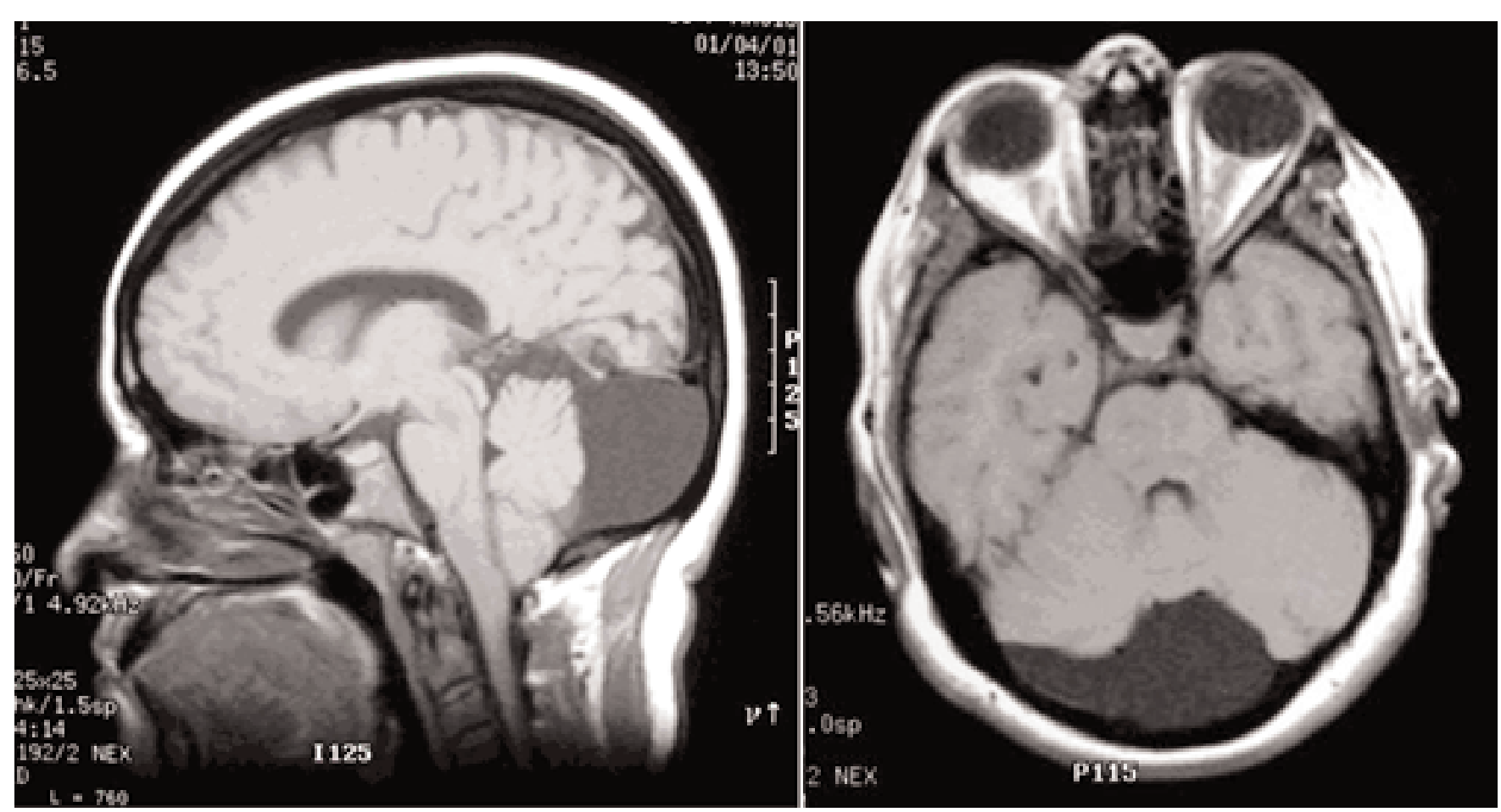

Fig. 1. Preoperative sagittal (left) and axial (right) MR views of the brain revealing a large posterior fossa arachnoid cyst and caudal displacement of the cerebellar tonsils. 


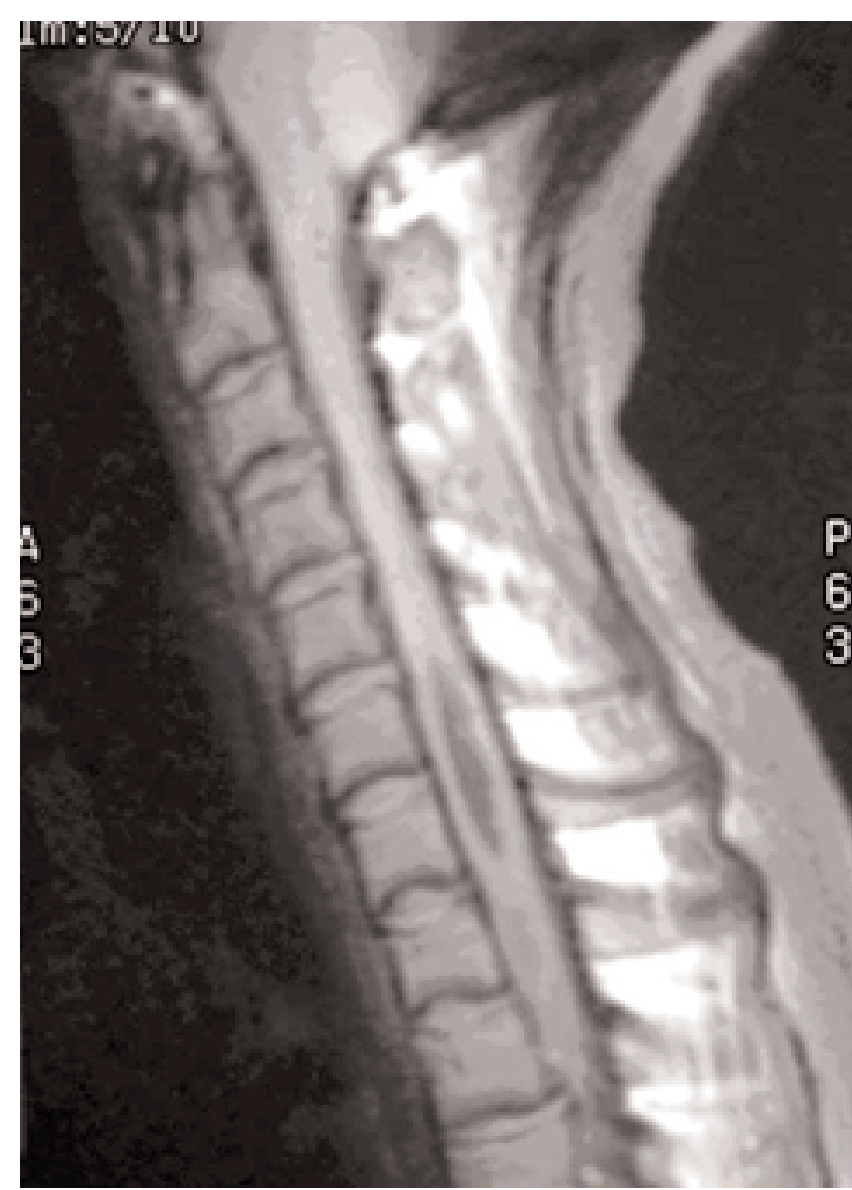

Fig. 2. Preoperative sagittal view of the cervical spine demonstrating syringomyelia.

memory and fatigue. She noted persistent pain in the scapular region and persistent numbness in the upper extremities and hands. A postoperative MR image of the brain, although demonstrating only a small decrease in the size of the posterior fossa fluid collection, revealed less deviation of the brainstem anteriorly and adequate decompression at the foramen magnum (Fig. 3 left and center). Follow-up cervical MR imaging, which was performed at 6 months, revealed complete resolution of the syrinx (Fig. 3 right). The patient's only complaint at the 6-month follow-up review was intermittent intrascapular pain that subsequently improved with physical therapy.

\section{DISCUSSION}

There has been one previous report of a patient with achondroplasia, posterior fossa cyst, syringomyelia, and cerebellar tonsillar ectopy, ${ }^{16}$ although treatment was not addressed in that paper. Evidence supports the hypothesis that the fundamental problem in the Chiari Type I malformation is a volumetrically small posterior cranial fossa. ${ }^{14}$ Indeed, this origin is highly probable in a patient with achondroplasia. The posterior fossa is formed by the endochondral ossification of the cartilaginous frame that forms the cranial base, as well as the first four embryonic somites that form the occipital bone. ${ }^{13}$ In a patient with achondroplasia, these structures would be expected to develop anomalously and to be smaller than normal.

The most common findings are a narrow, anteriorly displaced foramen magnum in a small, shallow posterior cranial fossa, and a small cisterna magna. ${ }^{16}$ The size of the foramen magnum in an adult patient with achondroplasia is comparable to its size at birth in an individual without this disorder. ${ }^{8}$ Interestingly, these abnormalities often result in upward displacement of the brainstem, sometimes in conjunction with angulation of the pons and medulla oblongata, ${ }^{16,22}$ possibly explaining the fact that Chiari Type I malformation is somewhat rare in the population with achondroplasia. In our patient, we hypothesize that the large arachnoid cyst in the already small posterior fossa resulted in a mass effect with caudal herniation of the cerebellar tonsils. This then led to obstruction of CSF flow at the foramen magnum and caused the formation of a large
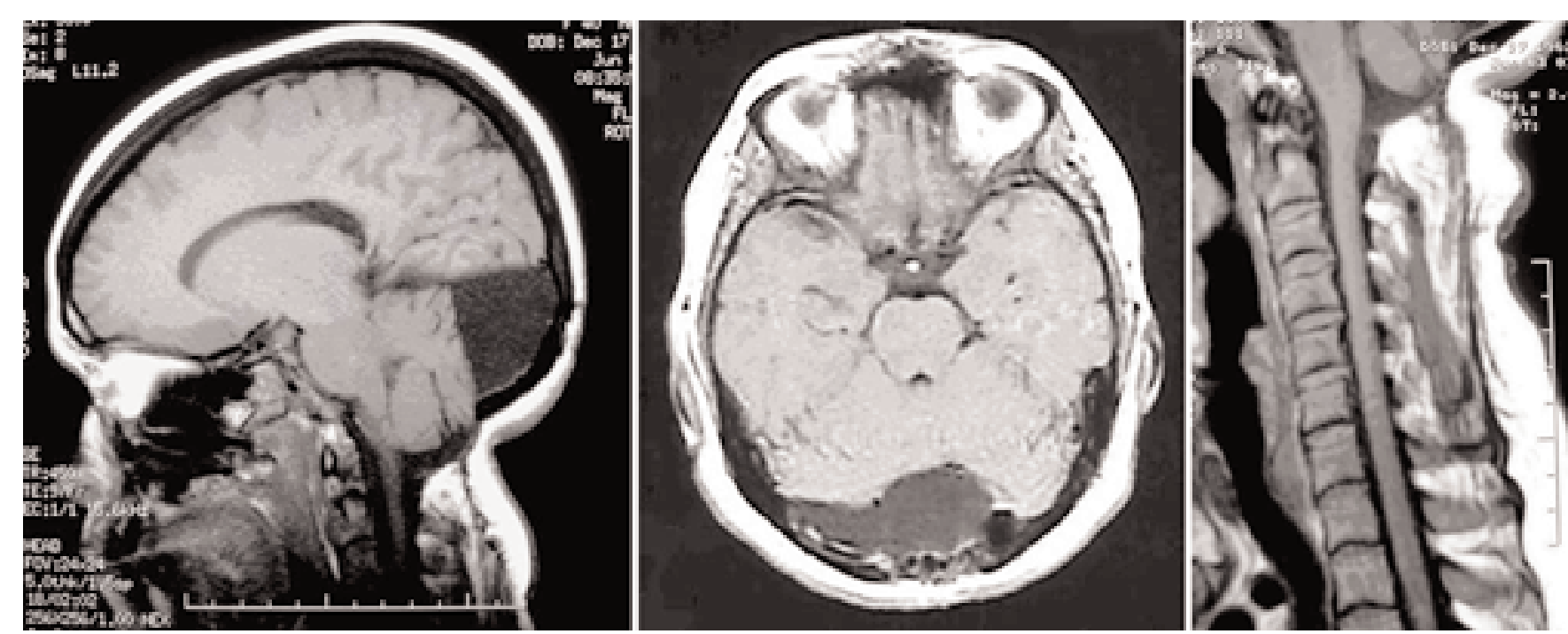

Fig. 3. Postoperative sagittal (left) and axial (center) brain and sagittal cervical spine (right) MR images demonstrating resolution of the syrinx. 
A. M. Bauer, D. M. Mueller, and J. J. Oró

TABLE 1

Literature review of syringomyelia in patients with posterior fossa arachnoid cysts*

\begin{tabular}{|c|c|c|c|c|c|c|}
\hline $\begin{array}{l}\text { Authors } \\
\& \text { Year }\end{array}$ & $\begin{array}{l}\text { Overview } \\
\text { of Study }\end{array}$ & $\begin{array}{l}\text { Patient } \\
\text { Age } \\
\text { (yrs), } \\
\text { Sex }\end{array}$ & Presentation & Neuroimaging Evaluation & Treatment & Outcome \\
\hline & \multirow{2}{*}{$\begin{array}{l}\text { three patients w/ } \\
\text { syringomyelia, } \\
\text { PF cyst, \& } \\
\text { hydrocephalus }\end{array}$} & $14, \mathrm{M}$ & $\begin{array}{l}\text { suffered from long-term } \\
\text { cerebral palsy; pre- } \\
\text { sented w/ progressive } \\
\text { lt-sided weakness in UE } \\
\text { more than LE (history of } \\
\text { traumatic delivery w/ } \\
\text { skull fracture); mild lt } \\
\text { facial weakness sparing } \\
\text { forehead; uvula deviated } \\
\text { to rt, tongue deviated to } \\
\text { lt; hyperreflexia w/ } \\
\text { extensor plantar reflex; } \\
\text { dysmetria \& past } \\
\text { pointing prominent on lt }\end{array}$ & $\begin{array}{l}\text { CT: obstructive hydro- } \\
\text { cephalus w/ large PF } \\
\text { cyst compressing 4th } \\
\text { ventricle; no com- } \\
\text { munication btwn cyst \& } \\
\text { ventricular system; } \\
\text { marked dilation of } \\
\text { cervical \& thoracic } \\
\text { spinal cord }\end{array}$ & $\begin{array}{l}\text { PF craniotomy w/ } \\
\text { removal of cyst } \\
\text { wall \& dorsal } \\
\text { myelotomy of } \\
\text { cervical spinal } \\
\text { cord }\end{array}$ & $\begin{array}{l}\text { symptoms stabilized w/ some } \\
\text { suggestion of improvement } \\
\text { in lt arm weakness; no fur- } \\
\text { ther progression of } \\
\text { patient's condition over 6- } \\
\text { yr FU }\end{array}$ \\
\hline & & $2, \mathrm{M}$ & $\begin{array}{l}\text { increasing head cir- } \\
\text { cumference; Dandy- } \\
\text { Walker syndrome di- } \\
\text { agnosed \& VP shunt } \\
\text { placed; on evaluation for } \\
\text { scoliosis, improvement of } \\
\text { hydrocephalus but no } \\
\text { resolution of cyst }\end{array}$ & $\begin{array}{l}\text { CT: large midline PF cyst, } \\
\text { which did not com- } \\
\text { municate w/ ventricular } \\
\text { system on contrast } \\
\text { myelography; myelogram: } \\
\text { extensive cervical } \\
\text { syringomyelia }\end{array}$ & $\begin{array}{l}\text { cystoperitoneal } \\
\text { CSF shunting }\end{array}$ & $\begin{array}{l}\text { CT: full collapse of cyst \& } \\
\text { syrinx; FU findings } \\
\text { demonstrated small 4th } \\
\text { ventricle, which suggested } \\
\text { that the original diagnosis } \\
\text { of Dandy-Walker syn- } \\
\text { drome was incorrect }\end{array}$ \\
\hline $\begin{array}{l}\text { Zager, et } \\
\text { al., } \\
1990\end{array}$ & $\begin{array}{l}\text { patient } \mathrm{w} / \mathrm{PF} \\
\text { arachnoid cyst } \\
\text { \& syringomyelia, } \\
\text { \& } 2 \text { patients w/ } \\
\text { syringomyelia due } \\
\text { to Chiari I } \\
\text { malformation }\end{array}$ & $9, \mathrm{~F}$ & $\begin{array}{l}\text { large arachnoid cyst \& } \\
\text { obstructive hydro- } \\
\text { cephalus at age } 7 \text { wks; } \\
\text { after treatment, she pre- } \\
\text { sented at age } 9 \text { yrs w/ } \\
\text { HA \& midthoracic back } \\
\text { pain; she also had bilat } \\
\text { leg weakness \& spasticity, } \\
\text { \& urinary urgency }\end{array}$ & $\begin{array}{l}\text { obstructive hydrocephalus } \\
\text { \& large midline } \\
\text { arachnoid cyst of } \\
\text { posterior cranial fossa; } \\
\text { open exploration } \\
\text { demonstrated } \\
\text { syringomyelia fromT-3 } \\
\text { to T-6 }\end{array}$ & $\begin{array}{l}\text { treated at age } 7 \\
\text { wks w/ VP } \\
\text { shunt, which } \\
\text { became dis- } \\
\text { connected; at } \\
\text { age } 9 \text { yrs, spinal } \\
\text { canal was opened } \\
\& \text { syrinx drained } \\
\text { by needle as- } \\
\text { piration; another } \\
\text { catheter was } \\
\text { inserted into } \\
\text { arachnoid cyst \& } \\
\text { subsequently con- } \\
\text { nected to existing } \\
\text { VP shunt, which } \\
\text { was functional }\end{array}$ & $\begin{array}{l}\text { papilledema rapidly } \\
\text { improved; LE function } \\
\text { gradually improved, \& at } 6 \\
\text { mos patient showed only } \\
\text { slightly increased ankle } \\
\text { reflexes } \\
\text { d- }\end{array}$ \\
\hline $\begin{array}{l}\text { Nakai, et al., } \\
1995\end{array}$ & $\begin{array}{l}\text { patient w/ achon- } \\
\text { droplasia, PF } \\
\text { cyst, syringo- } \\
\text { myelia, \& ton- } \\
\text { sillar herniation }\end{array}$ & $19, \mathrm{~F}$ & HA \& numbness of limbs & $\begin{array}{l}\text { MRI: displacement of } \\
\text { medulla \& cerebellar } \\
\text { tonsils downward into } \\
\text { spinal canal; dilated lat } \\
\text { \& third ventricles; cere- } \\
\text { bellum displaced an- } \\
\text { teriorly by arachnoid } \\
\text { cyst; cervical } \\
\text { syringomyelia }\end{array}$ & not reported & not reported \\
\hline $\begin{array}{l}\text { Wakamoto } \\
\text { \& Ko- } \\
\text { bayashi, } \\
1996\end{array}$ & $\begin{array}{l}\text { patient w/ PF } \\
\text { arachnoid cyst } \\
\text { w/ syringo- } \\
\text { myelia }\end{array}$ & $47, \mathrm{~F}$ & $\begin{array}{l}\text { history of skull fracture at } \\
\text { birth; presented w/ } \\
\text { occipitalgia, hydro- } \\
\text { cephalus, pain in rt } \\
\text { shoulder \& hand, } \\
\text { coughing, \& hiccuping }\end{array}$ & $\begin{array}{l}\text { large midline PF cyst w/ } \\
\text { syrinx extending from } \\
\text { C-1 to T-11 }\end{array}$ & $\begin{array}{l}\text { cystoperitoneal } \\
\text { CSF shunting }\end{array}$ & $\begin{array}{l}\text { resolution of symptoms \& } \\
\text { syrinx at 2-mo FU }\end{array}$ \\
\hline
\end{tabular}


TABLE 1 (continued)

Literature review of syringomyelia in patients with posterior fossa arachnoid cysts*

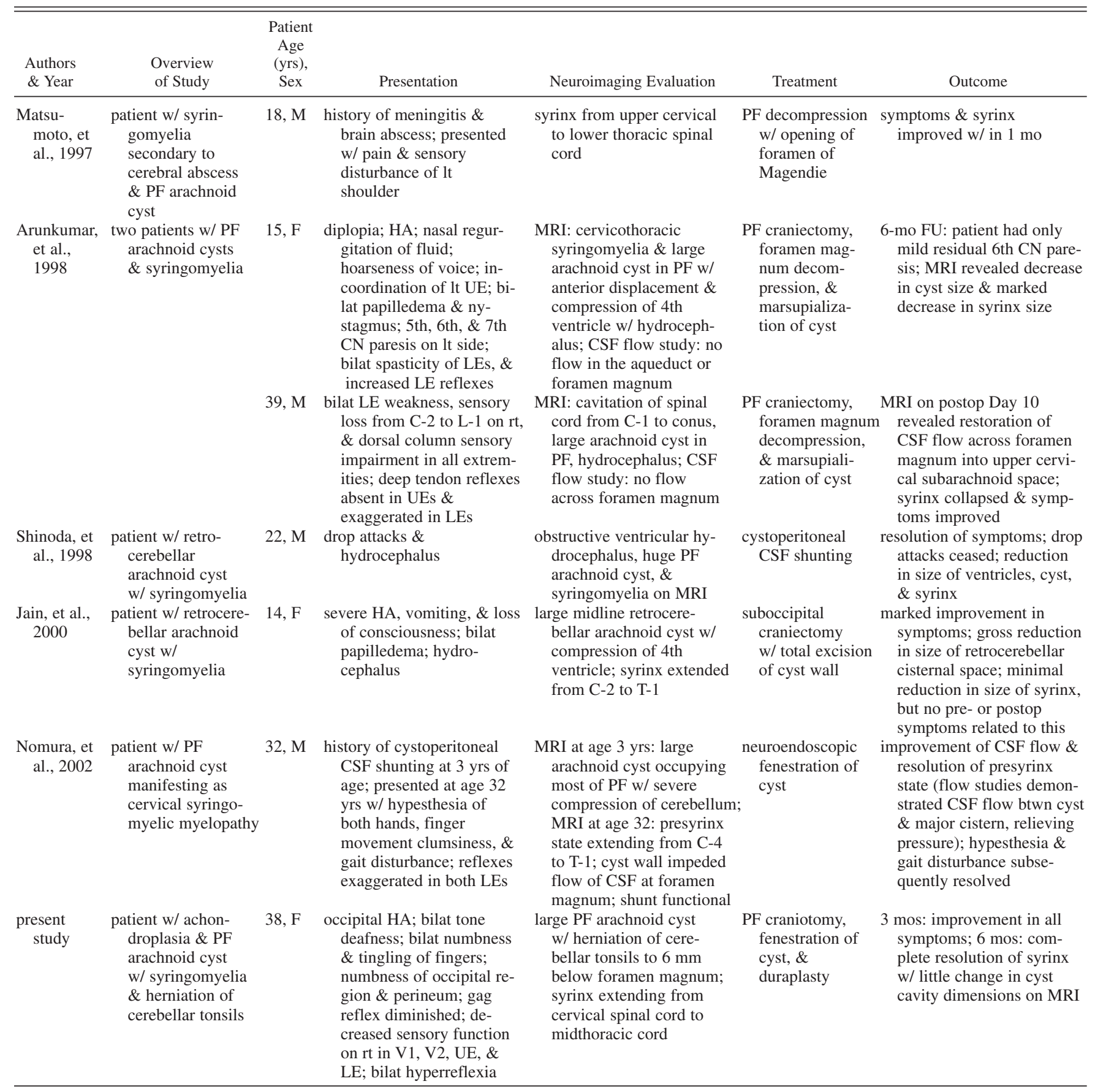

* Btwn = between; $\mathrm{CN}=$ cranial nerve; $\mathrm{CT}=$ computerized tomography; $\mathrm{FU}=$ follow up; $\mathrm{HA}$ = headache; $\mathrm{LE}=$ lower extremity; $\mathrm{PF}=$ posterior fossa; $\mathrm{UE}=$ upper extremity; $\mathrm{VP}=$ ventriculoperitoneal.

cervicothoracic syrinx.

The pathophysiological origin of syringomyelia has been the focus of several theories. The hydrodynamic theory proposed by Gardner, et al., ${ }^{7}$ in 1957 hypothesized that syrinx formation is the direct result of blockade of the outlets of the fourth ventricle. This leads to CSF being forced caudally into the spinal cord, with each arterial pulsation caus- ing increased pressure within the canal and dilation of the cavity, thus forming a syrinx. Another theory, set forth by Williams, ${ }^{25}$ holds that Valsalva maneuvers lead to increased intraabdominal and thoracic pressure, which is transmitted to the venous system of the Batson plexus and into the spinal subarachnoid space. This causes a net outflow of CSF from the spinal to the intracranial subarachnoid space. 
The posterior fossa cerebellar tonsillar herniation acts as a ball valve, restricting the passage of CSF back from the intracranial to the spinal subarachnoid space and creating a pressure differential between the subarachnoid space in the spinal canal and the cranium. The decreased pressure in the spinal subarachnoid space acts as a vacuum, pulling CSF down into the central spinal cord.

Ball and Dayan ${ }^{3}$ postulated that the pressure in the spinal subarachnoid space may increase with arterial pulsations and with blockage at the foramen magnum, and that CSF is thus forced into the central canal or into a cystic formation through the Virchow-Robin spaces of the spinal cord parenchyma. The Ball and Dayan hypothesis combined with elements of the others seems most appropriate in cases of a posterior fossa arachnoid cyst, and the theory has been substantiated using dynamic CSF flow (or cine) MR imaging studies. ${ }^{1}$ In our patient, the cyst and cerebellar tonsils were forced downward with CSF pressure at each systolic beat. The arachnoid cyst resulted in caudal displacement of the cerebellar tonsils, which act as a ball valve at the rostral end of the spinal column, blocking CSF flow in or out of the spinal subarachnoid space. When pressure is increased within the spinal subarachnoid space by Valsalva maneuvers or normal systolic pulsations, CSF is forced into the spinal cord parenchyma and collects to form a syrinx. In this model, the syrinx does not have to be in communication with the central canal and does not necessarily collapse immediately when CSF flow dynamics are restored.

According to recent literature, the most effective treatment of syringomyelia is deactivation of the filling mechanism. ${ }^{11}$ In our patient the filling and maintenance pressures for the syrinx were maintained by blockage at the foramen magnum. Thus, the focus of the surgical intervention in this case was fenestration of the cyst and expansion of the foramen magnum. Although it is possible that the tonsils would have ascended with cyst fenestration alone, the presence of the syrinx led the treating surgeon to expand the foramen as well. Nomura, et al. ${ }^{17}$ advocate the use of endoscopic fenestration of the lesion in treatment of arachnoid cyst and syringomyelia. Nevertheless, in light of the already deformed posterior fossa secondary to achondroplasia, a full suboccipital craniectomy with C-1 laminectomy, shrinkage of the tonsils, fenestration of the cyst, and duraplasty was performed. This allowed for good relaxation in the region of the foramen magnum and reestablishment of an adequate cisterna magna. With improved CSF flow dynamics, the syrinx began to shrink in size and at 6 months neuroimaging studies revealed that it had completely resolved. The symptoms related to the syrinx also resolved over this time.

A review of the English-language literature located case reports of 12 patients with posterior fossa arachnoid cyst and syringomyelia (Table 1). Of these, six underwent suboccipital craniotomy with fenestration of the cyst and decompression of the foramen magnum., ${ }^{1,4,9,12}$ Symptoms resolved in all cases but one ${ }^{4}$ in which the patient's symptoms remained unchanged. The syrinx also resolved on follow-up neuroimaging in all patients but one, ${ }^{9}$ in whom there was minimal resolution of the syrinx but improvement symptomatically. Two patients were treated with cystoperitoneal shunt placement, which resulted in decreases in syrinx size and resolution of symptoms in both cases. ${ }^{21,23}$ Two patients were treated with insertion of both ventriculoperitoneal and cystoperitoneal shunts, ${ }^{4,26}$ and symptoms cleared in both; however, the reports did not mention resolution of the syrinx on neuroimaging. One case was treated with endoscopic fenestration as mentioned earlier, ${ }^{17}$ and resulted in resolution of symptoms and the syrinx. These findings lead us to suggest that all of the aforementioned treatments are effective in the management of syringomyelia caused by a posterior fossa arachnoid cyst. Suboccipital craniotomy with open cyst removal offers the benefit of allowing the relaxation of the entire foramen magnum and the opportunity to explore the area to relieve any arachnoid adhesions that may further restrict flow.

\section{CONCLUSIONS}

We present a case report summarizing treatment in a patient with the endochondral bone formation defect of achondroplasia, in whom a large arachnoid cyst in the posterior fossa resulted in tonsillar herniation and syringomyelia. The defect in cartilage formation resulted in the development of a long, thin supraocciput, and the cyst caused anterior deviation of the cerebellar hemispheres and brainstem. Herniation of the cerebellar tonsils resulted in obstruction of CSF flow and resultant syringomyelia. Surgical treatment with cyst fenestration, tonsillar shrinkage, and duraplasty resulted in significant clinical improvement and resolution of the syrinx.

\section{References}

1. Arunkumar MJ, Korah I, Chandy MJ: Dynamic CSF flow study in the pathophysiology of syringomyelia associated with arachnoid cysts of the posterior fossa. Br J Neurosurg 12:33-36, 1998

2. Aryanpur J, Hurko O, Francomano C, et al: Craniocervical decompression for cervicomedullary compression in pediatric patients with achondroplasia. J Neurosurg 73:375-382, 1990

3. Ball MJ, Dayan AD: Pathogenesis of syringomyelia. Lancet 2:799-801, 1972

4. Banna M: Syringomyelia in association with posterior fossa cysts. AJNR Am J Neuroradiol 9:867-873, 1988

5. Bejjani G, Cockerham K: Adult Chiari malformation. Contemp Neurosurgery 23:1-7, 2001

6. Cakirer S: Arachnoid cyst of the craniospinal junction: a case report and review of the literature. Acta Radiol 45:460-463, 2004

7. Gardner WJ, Abdullah AF, McCormack LJ: The varying expressions of embryonal atresia of the fourth ventricle in adults: Arnold-Chiari malformation, Dandy-Walker syndrome, "arachnoid" cyst of the cerebellum, and syringomyelia. J Neurosurg 14:591-607, 1957

8. Hecht JT, Horton WA, Reid CS, et al: Growth of the foramen magnum in achondroplasia. Am J Med Genet 32:528-535, 1989

9. Jain R, Sawlani V, Phadke R, et al: Retrocerebellar arachnoid cyst with syringomyelia: a case report. Neurol India 48:81-83, 2000

10. Keiper GL Jr, Koch B, Crone KR: Achondroplasia and cervicomedullary compression: prospective evaluation and surgical treatment. Pediatr Neurosurg 31:78-83, 1999

11. Mallucci CL, Stacey RJ, Miles JB, et al: Idiopathic syringomyelia and the importance of occult arachnoid webs, pouches and cysts. Br J Neurosurg 11:306-309, 1997

12. Matsumoto H, Masuo O, Kuwata T, et al: [Syringomyelia appearing in a short term after brain abscess.] No Shinkei Geka 25:277-282, 1997 (Jpn)

13. Menezes AH: Embryology, development, and classification of 


\section{Arachnoid cyst with tonsillar herniation and syringomyelia}

disorders of the craniovertebral junction, in VanGilder JC, Menezes AH, Dolan KD (eds): The Craniovertebral Junction and its Abnormalities. Mt. Kisco, NY: Futura Publishing, 1987, p 4

14. Milhorat TH, Chou MW, Trinidad EM, et al: Chiari I malformation redefined: clinical and radiographic findings for 364 symptomatic patients. Neurosurgery 44:1005-1017, 1999

15. Morgan DF, Young RF: Spinal neurological complications of achondroplasia. Results of surgical treatment. J Neurosurg 52: 463-472, 1980

16. Nakai T, Asato R, Miki Y, et al: A case of achondroplasia with downward displacement of the brain stem. Neuroradiology 37:293-294, 1995

17. Nomura S, Akimura T, Imoto H, et al: Endoscopic fenestration of posterior fossa arachnoid cyst for the treatment of presyrinx myelopathy-case report. Neurol Med Chirur (Tokyo) 42: 452-454, 2002

18. Pinna G, Allessandrini F, Alfieri A, et al: Cerebrospinal fluid flow dynamics study in Chiari I malformation: implications for syrinx formation. Neurosurg Focus 8(3):E3, 2000

19. Ruiz-Garcia M, Tovar-Baudin A, Del Castillo-Ruiz V, et al: Early detection of neurological manifestations in achondroplasia. Childs Nerv Syst 13:208-213, 1997

20. Ryken TC, Menezes AH: Cervicomedullary compression in achondroplasia. J Neurosurg 81:43-48, 1994

21. Shinoda S, Tanaka K, Kawaguchi K: [A huge retrocerebellar arachnoid cyst with syringomyelia: case report.] No Shinkei Geka 26:363-367, 1998 (Jpn)

22. Thomas IT, Frias JL, Williams JL, et al: Magnetic resonance imaging in the assessment of medullary compression in achondroplasia. Am J Dis Child 142:989-992, 1988

23. Wakamoto H, Kobayashi K: [Syringomyelia associated with posterior fossa cyst: a case report.] No Shinkei Geka 24: 939-943, 1996 (Jpn)

24. Wang H, Rosenbaum AE, Reid CS, et al: Pediatric patients with achondroplasia: CT evaluation of the craniocervical junction. Radiology 164:515-519, 1987

25. Williams B: On the pathogenesis of syringomyelia: a review. J R Soc Med 73:798-806, 1980

26. Zager EL, Ojemann RG, Poletti CE: Acute presentations of syringomyelia. Report of three cases. J Neurosurg 72:133-138, 1990

Manuscript received August 1, 2005.

Accepted in final form September 14, 2005.

Address reprint requests to: Diane M. Mueller, N.D., R.N., C.F.N.P., Division of Neurosurgery, University of Missouri-Columbia School of Medicine, N521 1 Hospital Drive, Columbia, Missouri 65212. email: muellerdm@health.missouri.edu. 